\title{
EARLY OPHTHALMOLOGISTS IN CALCUTTA
}

BY

\author{
Lt.-Col. E. O'G. KirWaN, F.R.C.S.I., I.M.S. \\ PROFESSOR OF OPHTHALMOLOGY \\ MEDICAL COLLEGE hosPitals, CALCUTTA
}

During the régime of the Honourable East India Company the first properly organised Hospital, the Calcutta General Hospital, was established in 1790 in Calcutta. This was followed in 1792 by the opening of the Calcutta Native Hospital. The former is now represented by the present Presidency General Hospital, the latter was rebuilt and re-named and is now the present Mayo Hospital which was opened in 1874. The Calcutta Native Hospital appears to have been the first institution to provide scientific treatment for diseases of the eye, and even to this day, in spite of many other hospitals for the treatment of eye diseases, the Mayo Hospital still has the reputation among the inhabitants of Bengal as a place from which blind persons return with their sight restored.

Dr. John Shoolbred was the first Surgeon and Superintendent of the Calcutta Native Hospital and remained in charge of that institution from 1792-1816. In the year 1798 he published in the annual transactions of the hospital the treatment of two cases of cataract, twenty cases of phlegmon of the eyes and thirty cases of ophthalmia. He does not, however, give an account of the details of treatment. The number of eye cases reported in the annual hospital transactions steadily increased from year to year. He held the appointment of Superintendent and Surgeon to the Calcutta Native Hospital throughout his whole service, till he went on furlough in 1818 prior to retirement, with two intervals, one of furlough and the other when he acted as Superintendent General of Vaccination in 1806-1807.

Dr. Shoolbred obtained the Certificate of Surgeons in 1785, and served as Surgeon of the Indiaman "General Goddard" in 1789-90. He was commissioned as Assistant Surgeon in 1794, became Surgeon in 1807, retired in 1821 and died in 1831 .

Official records dated October, 1816, show that operations for the relief of blindness, including cataract, were first done in Calcutta by Surgeon Thomas Luxmore. He applied to the Right Hon'ble the Governor General in Council for a grant and an allowance for the upkeep of the small hospital he established in Chowringhee in 1816 and pointed out that the various opportunities he had in the operation of cataract had afforded him the pleasing gratification of rendering the operation so successful as generally to restore the sight of those who were blind from any species of cataract from the infant born in that state to the adult in the 
advanced period of life, provided there was no other defect in the organs of sight. He mentions that Drs. Cochrane and Leny, of the Medical Board, Bengal, inspected minutely the cases of cataract in his hospital and were pleased with the results of the new mode of treatment. The Governor General in Council, the Right Hon. Francis, Earl of Moira, K.G., sent in the application of Dr. Luxmore to the Medical Board in Calcutta asking if an institution could be established for boys from the Orphan and Free Schools to be instructed by Dr. Luxmore in the mode of extracting cataracts, and in the treatment of other diseases of the eye. Dr. R. Leny, Secretary of the Medical Board, replied that the Medical Board was of the opinion that no advantage could be gained from instructing young men from the Orphan and Free Schools in the mode of performing the operation for the cure of cataract and for the treatment of other diseases of the eye. From the delicacy as well as the complicated structure of the organ not only are the operations to be performed on it of a fine and difficult nature, but the proper treatment of its diseases requires an extreme range of knowledge. It appears, therefore, more necessary in respect to the eye more than perhaps any other organ of the human body that its professional management should be confined to persons better informed and more skilful than boys from the Orphan and Free Schools. It is likewise proper to remark that boys could not at present be furnished for such a purpose by these establishments, for a number of boys, not less than fifty, is now required for completing the new hospital establishment and a very small proportion of them can be supplied.

The matter was referred to Dr. John Shoolbred, the Surgeon Superintendent of the Calcutta Native Hospital as to whether he considered a ward contiguous to the Native Hospital could with advantage be constructed for the reception of natives affected with cataract and other diseases of the eye. He replied that as there were prejudices amongst many patients remaining as indoor patients, there was no necessity at present as cases of cataract and other chronic affections of the eye requiring operation, so long as they were not contagious and could remain in the common ward without danger to anyone, could be accommodated in some of the spare cots which were always available in the hospital. He also was of the opinion that before the new ward was erected exclusively for diseases of the eye the necessity for it should be satisfactorily established by experience and this could easily be done if the Surgeon in charge of the hospital were directed to keep a register of eye patients for 12 months, separate from that of other patients and to ascertain by this means how many cases of diseased eyes in that period would require or derive benefit from such separate accommodation and how many would avail 
themselves of it were it offered to them. If the number of the latter were sufficient to warrant the expense of an additional ward, it would then be time enough to erect it. If not, eye cases would, of course, continue to be received as they have hitherto been as house or out patients at their own option, when not improper to mix with others, for any idea of compelling them to remain in hospital contrary to their own wish would be the certain means of deterring many from applying for relief at the hospital who might otherwise have derived benefit from it, both in these and other complaints. The first separate account of eye patients submitted was from September 1, 1816, to August 31, 1817. In the Government Gazette dated December 19, 1816, the following appears :- " A person blind received sight by the means of a surgical operation performed by Dr. Luxmore, who removed a cataract which was the cause of blindness."

Dr. Thomas Luxmore was born March 13, 1774. Assistant Surgeon September 8, 1813, M.R.C.S. 1820, Surgeon May 23, 1825. Died at Lucknow, October 2, 1828.

In 1825, Mr. Surgeon Breton, Superintendent of the Calcutta Medical Institution, presented to the Governors of the Native Hospital a tract on the eye and its appendages and another on cataract, for the use of the assistants at the Native Hospital and its subsidiary dispensaries. These were written in Hindustani, in the Persian and Nagree character and were intended for the use of the students of the Native Medical Institution in Calcutta. These tracts were printed in lithography. The Calcutta Medical Institution was founded in 1822 and Surgeon Breton was the second Superintendent. As Superintendent of the Native Medical Institution he taught the senior students the native mode of operating for cararact, as he was convinced by positive proof that this method, on account of its extraordinary simplicity and efficacy, was the safest for the students to adopt. It is on record that a Mussalman practitioner operated successfully on eleven patients in his presence. In 1826 he wrote an article on the native method of couching. He was an author of repute. In the annual records of the Calcutta Native Hospital from 1816 onwards mention is made of cases of cataract admitted for treatment. Eye diseases were classified under four headings, viz., nyctalopia, cataract, phlegmon of the eyes and ophthalmia.

Dr. Peter Breton was appointed Assistant Surgeon August 27, 1801, Surgeon August 22, 1814. He gave up promotion to Superintending Surgeon to retain his appointment of Superintendent of the Native Medical Institution in 1826. He died in Calcutta on November 18, 1830.

When Dr. John Shoolbred resigned the post of Surgeon and Superintendent of the Calcutta Native Hospital in 1816 he was 
succeeded by Dr. Simon Nicolson. Crawford says of Nicolson, he was the best known medical man of his time in Calcutta, perhaps we might say, of any time. He was born on July 5, 1779, in the Manse of Kiltarlity, Inverness, Scotland, of which parish his father was minister, and was educated at St. George's Hospital, London, where he was House Surgeon in 1801, M.R.C.S. 1802. He was assistant to Sir Everard Home in private practice until 1805 and was succeeded in that post by Sir Benjamin Brodie when the post fell vacant through Nicolson's acceptance of an appointment in India. He was appointed to the Madras Medical Service in 1806, but never joined that Presidency, being gazetted to the Bengal Medical Service as Assistant Surgeon in the Calcutta General Hospital. Except for one period of leave to the Cape, he spent the rest of his service and life in Calcutta. From 1807 to 1816 he served in the Calcutta General Hospital and in 1816 he succeeded Dr. John Shoolbred as Superintendent and Surgeon of the Calcutta Native Hospital, and during his time the number of eye cases treated in the Calcutta Native Hospital steadily increased from year to year. Unfortunately the annual reports show no details of treatment. In the records his name appears frequently as being associated with the teaching of students in the diseases of the eye. He and Dr. James Ranald Martin were amongst other examiners in the first final examination for the diploma issued by the Medical College, Calcutta, in 1838. At this examination eleven students presented themselves and four passed. He retired from the post of Surgeon and Superintendent of the Calcutta Native Hospital in 1830 on the grounds of ill health and was appointed a Governor of this Hospital by the Governor General in Council on the recommendation of the Board of Governors of the Calcutta Native Hospital in appreciation of his work for that Institution. Early in 1833 he went on two years' leave to the Cape. On his return in 1835 he was posted as Surgeon to the Calcutta European Hospital and held that post till he died twenty years later. In 1839 he was gazetted Superintendent Surgeon but was allowed to decline promotion and to retain his appointment in Calcutta. He retired on August 1,1855 , and died in Calcutta a week later on August 8, 1855, at the age of 76 years.

It was Nicolson who first brought James Ranald Martin into notice, recommending him in 1823 to the Governor General, Lord Amherst, to be sent to Hyderabad to treat Sir Charles Metcalfe, the Resident there, who was seriously ill. In 1830 Martin succeeded Nicolson as Superintendent and Surgeon of the Calcutta Native Hospital. He also took charge of Nicolson's practice while he was at the Cape.

Nicolson left no published works and nowadays he is almost forgotten, a mere name, but no officer in the I.M.S. ever stood 
higher in the public and private estimation of his contemporaries. Sir John Kaye has described him under the name of Nicholas Fitzsimon in a long-forgotten novel "Peregrine Pulteney." A retired Bengal civilian in the novel speaks of him as follows :"Nicholas Fitzsimon, everybody knows him in India-finest fellow in the world-kind, generous, trump of a fellow. Now I'll tell you, go to him-give you breakfast, tiffin, dinner, shelter, advice, everything. If you are sick, go to him, sure to cure you - sure to be kind to you-saved more lives than the invention of the lifeboat-a most excellent fellow-good Samaritan-sure to love him."

A picture of Nicolson, seated in a chair, hangs in the rooms of the Calcutta Asiatic Society and a photograph of this painting is published with this article.

The late C. R. Wilson, in his Descriptive Catalogue of Paintings in the possession of the Asiatic Society of Bengal, quotes two other references to Nicolson, which should be reproduced here. " His practice was only limited by the impossibility of performing more than a certain amount of work within a certain space of time. One carriage was always kept waiting, day and night, to enable him to attend to any call without delay."

In accepting his resignation, the Governor General, Lord Dalhousie, wrote to him as having long possessed:- "In a measure rarely equalled, the confidence and reverence of your professional brethren, the universal respect and esteem of the community amongst whom you have passed your days and the approbation and gratitude of the Government, to whose service you devoted a long course of valuable labours."

Dr. Simon Nicolson was succeeded in 1830 as Surgeon and Superintendent of the Calcutta Native Hospital by Dr. James Ranald Martin, one of the greatest medical men of his time in India and in the annual records of the Mayo Hospital mention is made of large numbers of eye cases that were treated during his time as Surgeon and Superintendent and it is of interest to know that the earliest official records of glaucoma in Calcutta are found in the old records of the Calcutta Native Hospital in 1830, in the year that Martin succeeded as Surgeon and Superintendent of that Institution. In that year James Ranald Martin records the treatment of four cases of sudden acute inflammation of the eyes with widely dilated pupils and included these in a list of 113 cases of ophthalmia, as at that time all inflammatory diseases of the eye were still classified under the general heading of ophthalmia. Definite mention of glaucoma treated by operation is found in the records of the department of Ophthalmology of the Calcutta Medical College when Dr. Archer was the Surgeon in charge, 1858-1870. The number of eye cases coming for surgical 


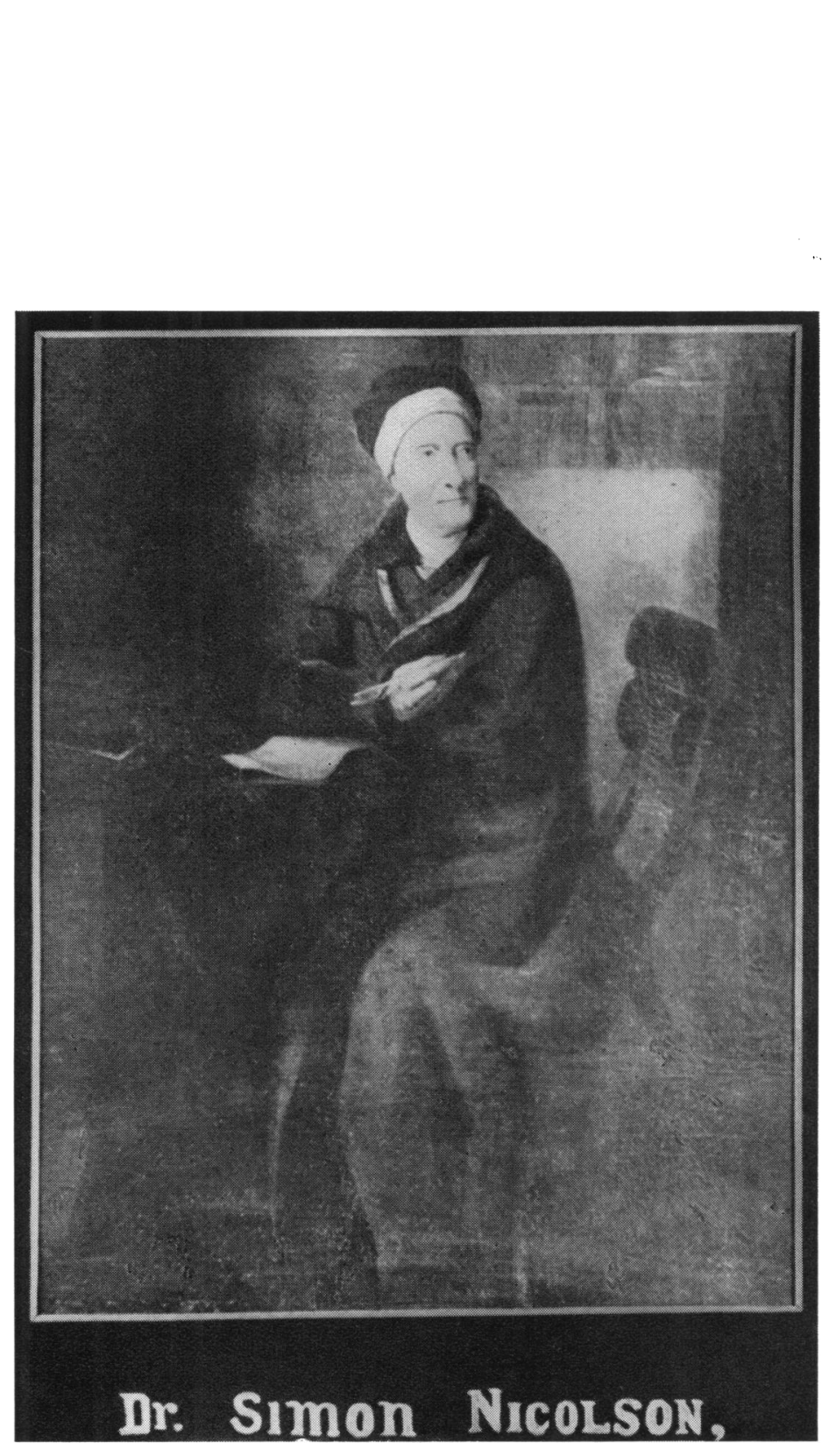

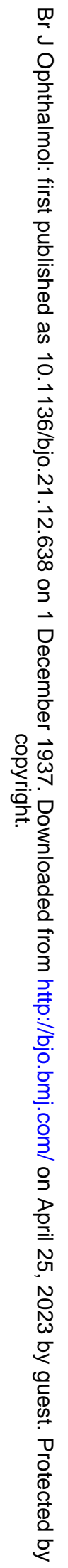




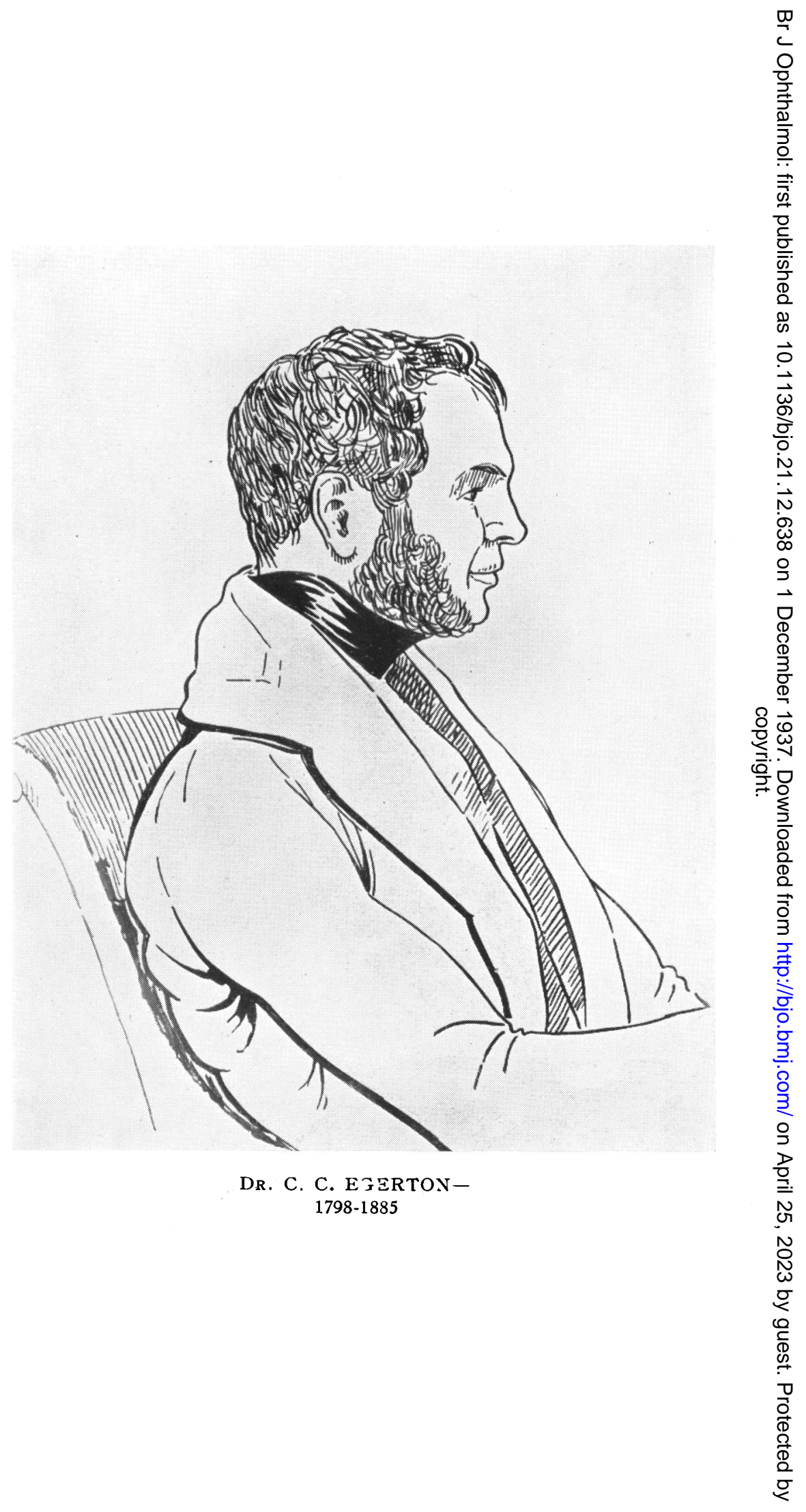




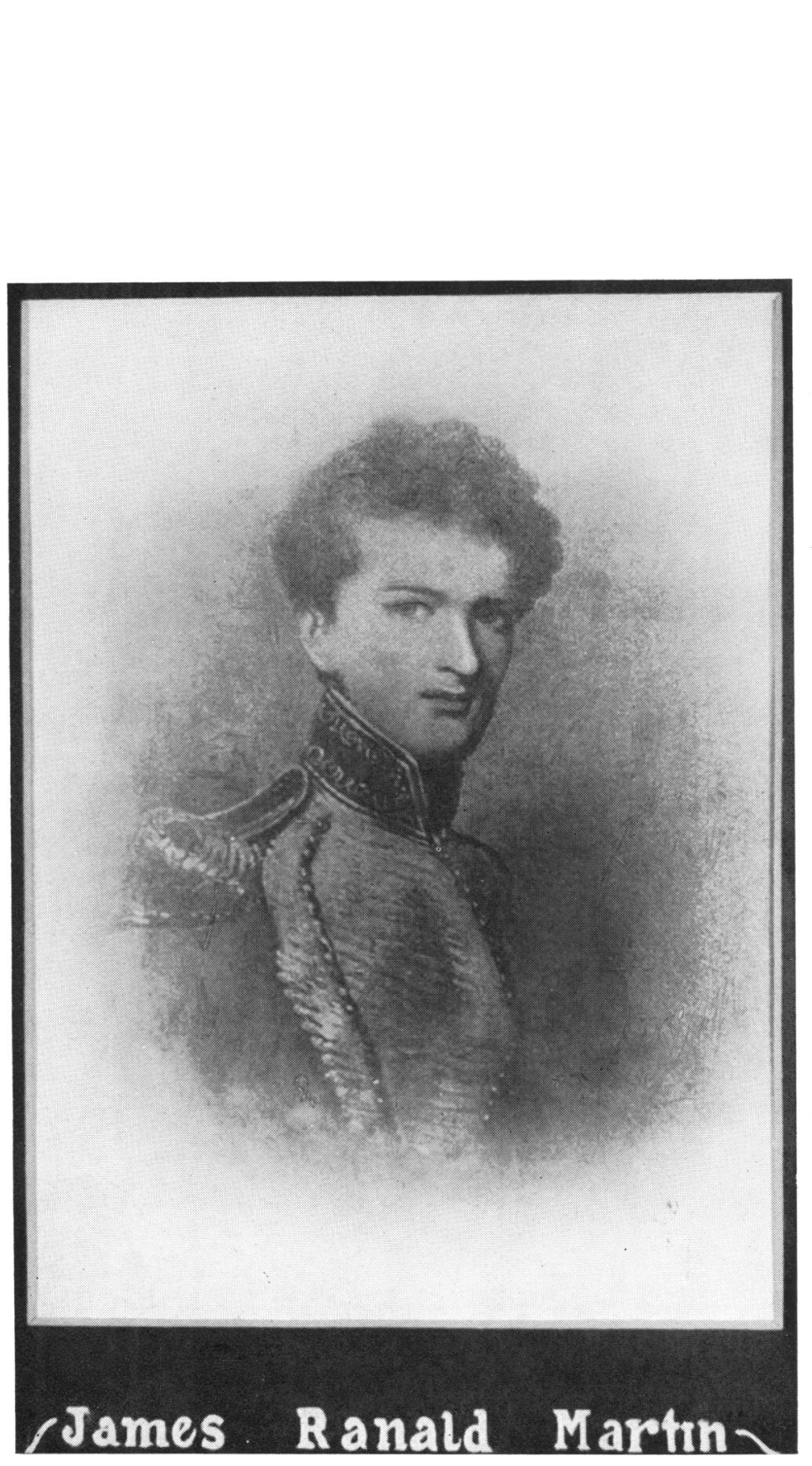

Surgeon (;overnor General's Bodyguarl), 1821 


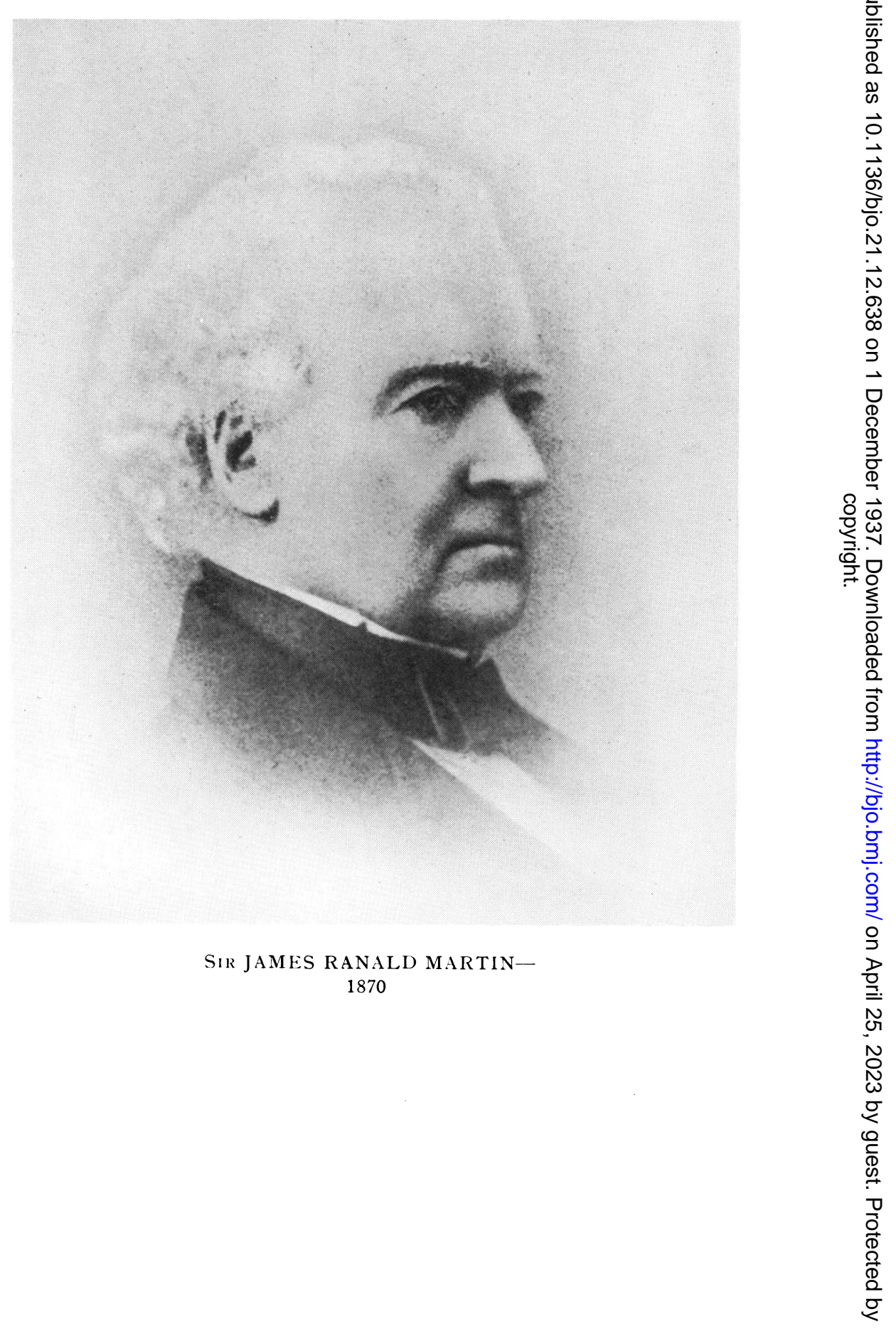


relief for glaucoma in those days was few and the popular belief was that operation on a glaucomatous eye was of no benefit except perhaps to allay pain. In the year 1835 the Calcutta Medical College with its associated hospitals was established and in the records of these institutions the earliest eye work mentioned was in 1840 and the name of Dr. Martin is associated with it. He was the first part-time Professor of Ophthalmology at the Medical College, Calcutta. He was the first to practise injections of iodine in the cure of hydrocele. A ward in the original Medical College Hospital, which was erected in 1848, was called the Martin Ward, to commemorate his services to humanity in Calcutta.

In 1839 he resigned the office of Surgeon and Superintendent to the Calcutta Native Hospital and the Governors of that Institution expressed themselves as follows :- "The Governors feel great regret at being called upon to accept your resignation, and particularly at the cause which has led to your retirement; at the same time they feel deeply sensible of the valuable services you have rendered to the institution over which they preside, of the great professional skill which for a period of more than nine years you have displayed in attendance on the native sick entrusted to your care, and of the zeal and ability you have constantly shown in offering numerous and important suggestions for the improvement of the institution over which you were placed."

To the Governor of Bengal they wrote:- "We take leave on this occasion to lay before you, Honorable Sir, copies of our correspondence with Mr. Martin, in the belief that it will be a source of satisfaction to Government, contributing as it does largely to this charitable institution, that it should be informed how very highly we appreciate the past services of Mr. Martin."

His friends and patients, at a meeting presided over by Sir John Peter Grant in the Town Hall, presented him with an address signed by over one hundred of the leading inhabitants, European and native, of Calcutta, and a gift of plate to the value of four hundred guineas.

On retirement from India in 1842 James Ranald Martin rapidly became a prominent figure in the medical world in England. He was appointed a member of the Health of Towns Commission and to him is due one of the most valuable appointments that was ever made in England, that of Medical Officer of Health. He sat on the Royal Commission to enquire into the conditions of the Royal Army Medical Department and was instrumental in founding the Army Medical School at Netley. His labours so benefited the Army that James Ranald Martin was widely spoken of as the soldiers' friend. His whole life was one of activity and usefulness and, whether in his public capacity or later in life in the private exercise of his profession, he was noted for the wisdom 
and judgment which he manifested and for the influence for good which he exercised on all with whom he was brought into contact. The Martin Memorial Gold Medal, presented to the surgeon on probation who takes the highest place in Military medicine at the Royal Army School at Millbank, London, at the close of each session, was created to commemorate his memory in advancing the science of tropical medicine and sanitation in India and at home, with the inestimable result of improving the health and diminishing the death rate of the Army in India.

James Ranald Martin was born on May 12, 1796, and was a pupil of Sir Everard Home, as well as of Sir Benjamin Brodie at St. George's Hospital, London. He was appointed Assistant Surgeon, Indian Medical Service, Bengal establishment, on September 5, 1817. Surgeon to the Bodyguard of the Governor General 1821-1826. Surgeon to the Governor General 1828 and Surgeon to the garrison of Fort William 1828. Appointed Surgeon of the Calcutta Native Hospital 1830. Retired 1842. Elected F.R.C.S. 1843. F.R.S. 1845. Appointed examining Physician to the Secretary of State for India 1859-1864. C.B. 1860. Knighthood 1860. President Medical Board, India Office, 1864 (when the Board was first formed) to 1874. Died in London November 27, 1874. Author of Medical Topography of Calcutta, 1830. Article on Hospitals in Holmes' System of Surgery, 1864.

In the History and Traditions of the Moorfields Hospital by Treacher Collins, mention is made that in $1824 \mathrm{Mr}$. C. J. Egerton, who had studied ophthalmology under Travers in the London Eye Infirmary, was sent to Calcutta, where he founded an Eye Hospital. This must be Charles Chandler Egerton, who was appointed to the I.M.S. as Assistant Surgeon in 1823. The eye hospital which was formerly situated at the junction of Wood Street and Theatre Road, Calcutta, on the present site of the Saturday Club and mentioned in old records, was probably started by him, but his name does not appear as holding a prominent position in ophthalmology. Bengal Civil Order No. 33 of February 1, 1837, shows that Assistant Surgeon C. C. Egerton was appointed Professor of Surgery and Clinical Surgery to the Calcutta Medical College. He held that position until he went on furlough in 1842 and was succeeded by Surgeon E. W. W. Raleigh.

Charles Chandler Egerton was born in April, 1798. Studied at Guy's and St. Thomas' Hospitals. M.R.C.S. 1819. Appointed Surgeon August 1, 1837. F.R.C.S. (elected) 1844. Retired January 31, 1847, and died in England on May 4, 1885.

\section{REFERENCES}

"Peregrine Pulteney" or "Life in India" in three volumes-London, John Mortimer, Adelaide Street, Trafalgar Square, 1844. Vol. I, Chapter V, p. 111 .

"History of the Indian Medical Service." Vols. I and II by Lt. Col. D. G. Crawford, I.M.S. 